\title{
Del espanto a la hilaridad en el relato cómico medieval
}

\author{
Cristina Azuela
}

Durante el Medioevo, los relatos de diablos y aparecidos fueron explotados sobre todo por la literatura edificante, como parte de una estrategia de la Iglesia para desmantelar creencias arraigadas desde épocas paganas. En este trabajo se examinan algunos relatos franceses e italianos (fabliaux y nouvelles) que retoman dichas creencias desde una perspectiva cómica. Así, en las Cent Nouvelles nouvelles encontramos historias casi contiguas que tocan un mismo tema, primero en clave seria y luego cómica, como rasgo de un género que reutiliza el material narrativo previo, parodiando las intenciones didácticas tradicionalmente ligadas con esos temas.

Palabras Clave: Fabliaux, Cent Nouvelles nouvelles, nouvelle 70, nouvelle 72, Estormi, aparecidos, diablo, parodia.

During the Middle Ages, stories about the devil and the returning of dead were mainly monopolized by didactic genres in an attempt of undermining the power of pagan beliefs. This paper examines some comic short stories, French and Italian (fabliaux and nouvelles), which rework the same material in a burlesque perspective. In the Cent Nouvelles nouvelles, two almost contiguous stories seem to reshape the same motifs but aiming to a completely different goal.

Key words: Fabliaux, Cent Nouvelles nouvelles, nouvelle 70, nouvelle 72 , Estormi, returning of dead, devil, parody. 

Cristina Azuela

Instituto de Investigaciones Filológicas

Universidad Nacional Autónoma de México

\section{Del espanto a la hilaridad en el relato cómico medieval}

El miedo ha acompañado a la humanidad a lo largo de su historia, y cada cultura elabora los motivos que la estremecerán de acuerdo con su idiosincrasia. En su obra El miedo en Occidente, Jean Delumeau esboza un recuento de las distintas causas de espanto que han aquejado a los hombres (partiendo del siglo XIV); curiosamente, el temor a los muertos y a los aparecidos es uno de los primeros en su lista (vid. capítulo 2). Como el autor señala:

Antiguamente, el pasado no estaba verdaderamente muerto, y en cualquier momento podía hacer irrupción, amenazador, en el interior del presente. Los difuntos ocupaban un sitio, al menos durante cierto tiempo, [junto a los vivos] (Delumeau, El miedo, 119).

No es gratuito, por ejemplo, que durante toda la Edad Media e incluso en el siglo XVI se documenten juicios y condenas contra personas ya fallecidas, a quienes se llegó a exhumar para hacerlas objeto de ejecuciones póstumas ( $c f r$. Delumeau, El miedo, 121). Es muy probable que en esta, como en todas las épocas, la narrativa tradicional, difundida de manera oral, reflejara las creencias y los temores acerca de los difuntos y demonios que 
volvían del Más Allá. Cuando en el Medioevo pasaron por el tamiz de la escritura, los relatos así producidos casi se convirtieron en monopolio exclusivo de la literatura compuesta en latín. Emparentadas con los exempla y con las historias de santos, estas narraciones tenían propósitos aleccionadores y moralizantes, cuyo objeto primordial era confirmar la validez de los dogmas fundamentales y de los principales sacramentos de la doctrina cristiana. Se enfatizaba la utilidad de los sacramentos y de las enseñanzas de la Iglesia como defensa contra los seres fantasmales, al tiempo que se mostraba la realidad de la vida después de la muerte, del Paraíso y el Infierno —y a finales del Medioevo, del recién estrenado Purgatorio. ${ }^{1}$ Así, en esta época proliferan numerosos relatos de visiones y de difuntos que vuelven del otro mundo, sobre todo para confirmar la veracidad de los suplicios de los pecadores, y muy especialmente para exhortar a los vivos a que recen y digan misas por el perdón de sus faltas, para ayudarlos a cumplir las diversas penitencias que los mantienen en constante sufrimiento en el Más Allá. ${ }^{2}$

$\mathrm{Si}$ bien ciertos motivos ligados a las creencias en el retorno de los muertos llegan a convertirse en estereotipos literarios (bien documentados por José Manuel Pedrosa), ${ }^{3}$ queda claro que ta-

${ }^{1}$ Como lo demostró Le Goff, quien recuerda que la palabra purgatorium no existe como sustantivo hasta finales del siglo XII (El nacimiento del Purgatorio, 11; cfr. Beardsmore, “About the Seventieth", 235).

${ }^{2}$ Varvaro comenta que mientras se está conceptualizando la noción del purgatorio "los muertos no encuentran la paz", sus apariciones son frecuentísimas y su reintegración en los mecanismos sociales es continua y alarmante (Apparizioni Fantastiche, 138).

${ }^{3}$ Pedrosa, "Una leyenda gallega de fantasmas". Partiendo de la evocación de la muerte del rey Sancho Ordóñez de Galicia en el Cronicón Iriense, redactado en latín a finales del siglo IX — que por cierto, señala Pedrosa, incorporaba al relato del deceso del rey gallego las circunstancias en que falleció un monarca completamente diferente, Sancho I de León, envenenado y muerto en el año 966 mientras regresaba de Galicia a León-, el crítico examina cómo esta crónica se relaciona con otra, china, escrita entre los siglos III y v de nuestra era, donde el historiador Gan Bao en un tratado "supuestamente histórico" relata, como si fueran acontecimientos reales, una historia que comparte los mismos motivos folclóricos que aún se encuentran en 
les creencias formaban parte de la realidad cotidiana y los usos de la cultura, como los estudios antropológicos de los pueblos germánicos han demostrado (véase infra nota 4). Así, entre los más antiguos aparecidos se encuentran quienes vuelven a esta vida para suplicar que les sea otorgado un entierro acorde con los ritos mediante el cual puedan encontrar la paz y el descanso eternos. En otros casos, los muertos retornan a este mundo con una petición específica que el difunto no pudo hacer en vida, o por la necesidad de satisfacer alguna venganza, y en último caso, también vuelven para retribuir o recompensar algún bien recibido. ${ }^{4}$

En sus estudios sobre los aparecidos y los fantasmas medievales, ${ }^{5}$ Claude Lecouteux explica cómo la creencia en los seres que vuelven de la otra vida constituyó durante el Medioevo un claro vestigio de la ideología y los rituales paganos. Basándose en textos nórdicos — sobre todo en sagas islandesas y noruegas (que, no debemos olvidarlo, ya pasaron por una pluma cristianizada, pero igual son testimonios invaluables) - y en otros germánicos y latinos, el estudioso traza el camino que lleva de la veneración celta y nórdica de los ancestros al surgimiento de fantasmas insustanciales y diablos en la época medieval.

En este trabajo retomo las indagaciones de Lecouteux y las de otros investigadores (Binski, Russell, Le Goff, Schmitt, Walter) sobre las nociones de la muerte, las costumbres funerarias

leyendas urbanas actuales. Es decir, ambas crónicas o "historias" pretenden narrar hechos sucedidos, cuando en realidad parece evidente que se trata de construcciones transmitidas donde los motivos literarios y folclóricos reaparecen casi intactos a pesar de las distancias geográficas y temporales. Véase también el extenso prólogo que dedica a su libro La autoestopista fantasma y otras leyendas urbanas españolas (Madrid, Páginas de Espuma, 2004). Agradezco a este autor los valiosos comentarios y referencias bibliográficas acerca de este tema.

${ }^{4}$ En Au-delà du merveilleux, Lecouteux hace un recuento bastante claro de las causas del retorno de los muertos. Y Varvaro ofrece múltiples ejemplos tomados de los relatos de Walter Map.

${ }^{5}$ Vid. Fantasmas y aparecidos en la Edad Media, y también supra, la nota precedente. 
y las creencias en el Más Allá de paganos y cristianos. Ello me permitirá constatar que el hombre ha encontrado maneras muy diversas de enfrentar los temores más acendrados que le acosan. Una de tales estrategias, sin lugar a dudas, ha sido el convertir sus miedos y lo que los ocasiona en objeto de burlas y de risa.

Si bien la mayor parte de los textos en lenguas vernáculas que se ocupan de seres fantasmagóricos leen las apariciones en un registro serio, ${ }^{6}$ aquí voy a tocar una clase particular de historias de fantasmas y aparecidos ${ }^{7}$ del Medioevo: los relatos cómicos cuyos efectos burlescos dependen estrechamente de la actualidad de las creencias mencionadas. Éstos se encuentran en dos géneros principales: los fabliaux franceses y sus descendientes directas, las nouvelles italianas y francesas, que desde el siglo XIII hasta el final de la Edad Media retoman en clave jocosa la tradición narrativa seria de fantasmas y muertos vivos.

Abordaré pues un fabliau. ${ }^{8}$ En el fabliau de "Estormi", ${ }^{9}$ un marido asesina durante una misma noche a tres curas, quienes uno después del otro habían pretendido obtener los favores de su mujer a cambio de una cantidad de dinero. Una vez asegurado

${ }^{6}$ Beardsmore menciona algunas anécdotas insertas en obras largas, como la del duque Ricardo I de Normandía en el Roman de Rou, donde se habla explícitamente de "fantosmes"; o bien la aventura del hijo de Ysaye le Triste (novela arturiana tardía), Marc, quien gracias a la confesión puede enfrentar a un espíritu que lo había atacado ya en dos ocasiones (“About the Seventieth", 236-237). Lecouteux alude también a los aparecidos en la obra de Chrétien de Troyes, pero este mismo autor se pregunta por qué no hay tanta presencia de estos temas ni en la novela ni en la épica, o incluso en los fabliaux (Au-delà du merveilleux, 262).

${ }^{7}$ El término "aparecidos" no corresponde a la época. Schmitt precisa que en latín más bien se hablaba de similitudo, imago, y a veces figura, persona, forma ("Les masques, le diable, les morts", 96). De este mismo autor hay que mencionar el libro Les Revenants: les vivants et les morts dans la société médiévale, Paris, Gallimard, 1994.

${ }^{8}$ Género francés de relato breve en verso que surge a finales del siglo XII y se populariza durante el XIII.

${ }^{9}$ Cito a partir de la edición diplomática de Noomen y van der Boogart (NRCF), 6-12, aunque para las traducciones tomo la puntuación de la más accesible antología Fabliaux du Moyen Âge, editada por Dufournet (con una impecable versión en la lengua original y su traducción al francés moderno), 254-287. Todas las traducciones al español son mías. 
el capital de sus víctimas, los esposos se ven obligados a deshacerse de los tres cadáveres, cosa que realizarán de manera particularmente astuta, pues irán disponiendo de ellos como si se tratara de uno solo. Para lograrlo revelan a un sobrino, Estormi, la pretensión lujuriosa de un cura hacia la tía, y cómo el marido lo golpeó, matándolo sin querer; pero necesitan enterrarlo antes de que alguien los sorprenda. El sobrino acepta ayudarlos a ponerlo bajo tierra, pero cuando regresa a la casa habiendo cumplido su misión el tío le muestra el cuerpo de otro de los curas, lamentando que el muerto haya decidido regresar para que la evidencia lo inculpe ante las autoridades. De esta manera, Estormi carga a sus espaldas tres veces al que piensa es un solo difunto, con el fin de llevarlo a enterrar al campo, sólo para volver a encontrarlo en la casa (las dos primeras ocasiones). Estormi parece atribuir la reaparición del cadáver a algún diablo que se burla de él, tanto cuando supone que "debe tener al diablo en el cuerpo / pues son ellos los que los trajeron de regreso"; 10 o también en el momento de apostrofar al muerto: "Bien conocido habéis de ser en el Infierno / que os han traído acá". ${ }^{11}$

Al mismo tiempo, el joven no deja de considerar el retorno de los cuerpos como producto de la voluntad del muerto, y por ello lo interpela: “¿Así que es por la dama por lo que regresáis tan pronto? Ningún espanto va a impedirme enterraros". ${ }^{12}$

De esta manera, en la historia jamás se cuestiona la vitalidad del difunto, su deseo de volver ni su capacidad para hacerlo sin ningún problema.

$\mathrm{Al}$ inhumar al tercer cura, Estormi tropieza y cae al foso con el cadáver encima. Al desplomarse, el brazo de éste le pega en la cara. Sorprendido, exclama:

10 "Dont a il le deable el cors, / Qu'i l'ont raporté ça dedenz" (vv. 370-371).

11 "Bien estes en enfer connuz / Quant il vous ont ci raporté" (vv. 388-389).

12 "Restiiez ore por la dosne / Reuenuz si nouelement / Ja por nul espoentement / Ne lerai que ne vous enfueche" (vv. 396-399). 
Maldición, ipor el culo de Santa María!, [...] estoy frito. Este cura está resucitando ¡qué golpe me acaba de dar! No creo poder escapar, me está aplastando. ${ }^{13}$

Sin embargo, el relato culmina cuando por fin cree haber terminado de enterrar (por tercera vez) al "gordo y enorme" 14 cura; Estormi, agotado, se topa con un nuevo prelado, vestido con su capa negra - similar a la de los otros tres y, podemos suponer, pareciendo igual de fornido- - quien pasa satisfecho luego de cantar maitines. El joven, fastidiado ya, lo enfrenta:

Mira nomás, ya se me está escapando el cura. Por el culo de Dios, otra vez se va a regresar. ¿Qué te pasa curita, me quieres cansar? Ya me hiciste desvelarme toda la noche, pero no te va a servir de nada. ${ }^{15}$

Y precipitándose sobre él, le da tal golpe en la cabeza que le saca el cerebro (vv. 521-534), con lo que procede a deshacerse una vez más de aquél a quien nunca dejó de considerar como un pertinaz muerto vivo. Incluso, lo primero que hace al llegar con el tío es preguntar si el difunto volvió, y ante la negativa declara orgulloso que fue porque lo interceptó en el camino, para sorpresa del tío, quien se da cuenta de que por su causa habían sacrificado a un inocente — pero dados los rasgos anticlericales del género, el hecho no parece provocarle mayor culpabilidad.

13 "Vois por le cul sainte marie, / [...] ie sui matez. / Cist prestres est resuscitez / Com m'a ore doné bon frap /Je ne cuit que mes li eschap, / Que trop me foule et trop me mate" (vv. 488-493).

14 "Molt estoit cras et esfossez" (v. 428). A lo largo de toda la historia abundan los comentarios chuscos y despreciativos sobre los curas: por feos (v. 383), por lujuriosos (v. 97), pero sobre todo por gordos (vv. 341, 352, 428, 473, 504). En "El monje sacristán" el cadáver del cura —otro cadáver ubicuo, como abundan entre los fabliaux (vid. Bloch, The Scandal) - es confundido e intercambiado por el de un puerco, y abundan los juegos de palabras y las alusiones al puerco que es el cura (cfr. Fabliaux du Mogen Âge, 192-233).

15 “Vois fet il cil prestres m'eschape!/ Par le cul Dieu il s'en reua!/ Qu'est ce sire prestres diva,/ Me volez vous plus traueillier / Longuement m'auez fet veillier,/ Mes certes noient ne vous vaut!" (vv. 522-527). 
En este relato, al igual que en variantes tales como el fabliau de "Los tres jorobados", ${ }^{16}$ que comparte el motivo y casi todos los detalles de la intriga alrededor del supuesto retorno de un cadáver cuando en realidad hay tres muertos, queda claro lo familiar que al público medieval podría parecerle la eventualidad de que un muerto decidiera regresar - y con mayor razón uno que falleció por causas no naturales - ya fuera a cobrar venganza o a inculpar al asesino, tal como las creencias nórdicas lo señalaban, similares a las que el tío había esgrimido para convencer a Estormi.

Pero también sobresale el hecho de que ya se mezcla aquí la obra del demonio o los demonios y se confunden tradiciones: con los rasgos típicos de los vengativos aparecidos de las tradiciones paganas se entretejen las malas intenciones de los diablos cristianos. Ello tiene una razón:

Delumeau comenta las dos formas de concebir las apariciones de un muerto; una, la más antigua, "horizontal", naturalista y popular, basada en la noción de la supervivencia del doble, donde el difunto continuaba con su cuerpo y alma viviendo durante cierto tiempo y volvía a los lugares de su existencia terrestre. La otra concepción, "vertical" y trascendental, fue la de los teólogos, quienes la explicaban como resultado del juego entre las fuerzas espirituales (Delumeau, El miedo, 123). San Agustín, como veremos más adelante, postulaba que las apariciones no tenían alma ni cuerpo y eran simples imágenes del alma del muerto que adquirían visibilidad por medio del aspecto exterior del cuerpo de aquél (véase infra nota 22; Schmitt, "Les masques, le diable, les morts", 96).

${ }^{16}$ La coincidencia de los motivos de ambos relatos es tan puntual que incluye el asesinato injustificado de una cuarta víctima. También es notoria la atribución al diablo de las distintas "apariciones" por parte del encargado de deshacerse de los cadáveres. Este relato aparece traducido al español en la edición bilingüe de Felicia de Casas: Fabliaux. Cuentos franceses medievales, 137-153. 
Así pues, este intento de la Iglesia por neutralizar la fuerza de las creencias paganas se basaba en restarles materialidad, a la vez que las relacionaba con los poderes diabólicos; como consecuencia, por una parte los propios aparecidos terminaron convertidos en provocaciones demoniacas, y por la otra fueron perdiendo corporeidad para acabar como visiones, fantasmagorías y pesadillas. ${ }^{17}$

Por ello, la seguridad con que Estormi repite una y otra vez que la reaparición del cadáver se debe al demonio nos recuerda que el diablo solía divertirse a costa de quienes habían pecado (o habían hecho pactos con él), transformando los bienes que los humanos habían querido adquirir mediante la alianza en montones de excremento o cualquier otra cosa deleznable. ${ }^{18} \mathrm{Se}$ trataría, pues, de una típica venganza o burla satánica —que también puede verse como un castigo al asesinato, más a tono con las moralejas de los exempla.

Es evidente que a pesar de que la literatura clerical repudia todas las reminiscencias paganas, ella misma, como los trabajos de Philippe Walter han demostrado, se halla impregnada de éstas y no logra detener del todo su contagio al resto de la producción literaria. ${ }^{19}$

Por otra parte, hay que subrayar que la noción del regreso de los muertos no es exclusiva del pensamiento pagano. Como afirma Binski, se encontraba en la base de la ideología cristiana. Al comienzo de su estudio sobre la muerte en la Edad Media, este

${ }^{17}$ Véase infra nota 22. Es necesario señalar, sin embargo, que los sueños proféticos y de aparecidos también formaban parte de las tradiciones nórdicas y paganas. Tanto Walter como Lecouteux y Schmitt se extienden sobre el asunto de la "diabolización" de los aparecidos por parte de la cultura oficial.

${ }^{18}$ Cfr. Russell, Lucifer. Es conocida la capacidad del demonio para realizar toda clase de transformaciones que confunden a los humanos. Delumeau cita tratadistas de los siglos XVI y XVII que teorizan sobre esto (El miedo, 124).

${ }^{19}$ Véase su Mythologie Chrétienne (traducido al español como Mitología cristiana. Fiestas, ritos y mitos de la Edad Media [2004]), y en particular, con referencia a los aparecidos, su libro Le mythe de la chasse sauvage. Véase también Lecouteux, Fantômes et revenants, $10 \mathrm{y} A u$-delà du merveilleux. 
historiador recuerda que el milagro de la resurrección de Lázaro marca un momento crucial en la vida de Cristo. No sólo porque en adelante se iniciará la pasión, sino porque enfatiza uno de los rasgos centrales del cristianismo: el triunfo sobre la muerte. De hecho, la cristiandad había puesto a la muerte y a un muerto resucitado en el centro del drama de la salvación humana. La función de Cristo es justamente redimir los pecados de los hombres y asegurarles la resurrección para la vida eterna.

Sin embargo, precisa el crítico, para los “contemporáneos de Cristo, fueran judíos, gentiles o paganos greco-romanos, el que los muertos se levantaran era un hecho anormal y absolutamente transgresivo" (Binski, Medieval Death, 9), lo que coincide con el inmenso temor que entre los nórdicos, pero también entre los romanos, provocaban los difuntos cuando volvían a este mundo (Lecouteux, Fantômes et revenants), ${ }^{20}$ por lo que existían prácticas destinadas a impedir que regresaran a molestar o aterrar a los vivos: en algunas partes, por ejemplo, los sacaban por un agujero en la pared, que de inmediato rellenaban, ya que el muerto sólo puede entrar por donde salió; o los ataban con cuerdas y cadenas, o ponían piedras pesadas y losas sobre ellos, o los colocaban boca abajo - como quiere la tradición popular que se entierre a las suegras-, o les cortaban la cabeza y se la ponían entre los pies, o bien, ya cristianizados, les amarraban las manos con un rosario, etc. (Lecouteux, Fantômes et revenants, 33-45).

Por otro lado, era sabido que sólo a los criminales le interesaba regresar, o a aquellos que habían sufrido una muerte no natural (como los cadáveres de Estormi) y que no habían sido honrados por los ritos funerarios habituales (estos rasgos pare-

\footnotetext{
${ }^{20}$ Ante la costumbre germánica de enterrar a los muertos cerca de sus predios familiares, los cristianos los relegan a los cementerios allegados a las iglesias. Con eso, dice Binski (Medieval Death, 12), se urbaniza a los muertos. Aunque hay que notar que ya los romanos tenían lugares separados, al igual que los judíos, que consideraban impuro el contacto con los difuntos.
} 
cen ser compartidos entre todos los pueblos indoeuropeos [Lecouteux, Fantômes et revenants, 31]). ${ }^{21}$

Como ya se dijo, los aparecidos de los paganos sufrirán múltiples transformaciones a manos del cristianismo, que los llevará a ser conocidos como fantasmas incorpóreos o visiones (postura que parte de Tertuliano y San Agustín). ${ }^{22}$ Para los antiguos, en cambio, los aparecidos no se evaporaban simplemente ante una plegaria o ante el signo de la cruz, pues aunque eran entes que habían pasado a otra vida tenían un cuerpo, sentimientos y costumbres. Esto será asimilado más tarde con las apariciones diabólicas, ellas sí presentes con un cuerpo materializado. De igual manera que muchos de los seres divinizados por los paganos (los espíritus de la naturaleza, de los árboles o de los ríos y lagos, e incluso los duendes y las hadas), los reaparecidos pasarán a convertirse en distintas clases de demonios y seres malignos. ${ }^{23}$. Así pues, sólo tienen cabida los muertos de las visio-

${ }^{21}$ Dejando de lado a quienes eran obligados a volver por medio de invocaciones y magia, Delumeau, por su parte, añade otra "categoría de candidatos a aparecidos": los que habían muerto en el momento o en la proximidad de un rito de paso que, debido a este hecho, no se había llevado a cabo con éxito (fetos muertos, cónyuges fallecidos el día de las bodas, etc.). Cfr. El miedo, 137.

${ }^{22}$ Lecouteux, Fantômes et revenants, 52-55. Tertuliano afirma que todos los aparecidos son diablerías, ilusiones que el diablo nos hace creer, y utiliza el término "phantasma" como equivalente a "engaño". San Agustín examina primero el caso de los muertos sin sepultura, pero los liga a visiones en los sueños, y finalmente dice que todo es obra de Dios: las apariciones tienen el sentido de mensajes divinos que los ángeles nos transmiten a través de diferentes medios, entre ellos los muertos (54). Los ángeles buenos nos traen los sueños buenos, los ángeles malos los sueños falaces y los fantasmas (54); aunque el mismo Agustín postula contradictoriamente que los muertos sólo aparecen en sueños, su postura proporciona el arma esencial de los teólogos, que podrán así extirpar los rasgos paganos del culto de los muertos y otras creencias problemáticas ligadas a éstos (55).

${ }^{23} \mathrm{Al}$ estudiar la creencia en "la cacería salvaje" del Hellequin, y otras fechas tradicionales de apariciones de muertos, Walter subraya, en efecto, la coincidencia de las fechas paganas que aluden a ritos y tradiciones antiquísimas durante las cuales las fuerzas cósmicas desencadenadas y la apertura del paso entre el Más Allá y este mundo no sólo permiten la libre circulación de los seres del otro mundo, sino provocan alteraciones del equilibrio y la temporalidad cotidianos. Así, durante las fechas cuando antiguamente habría habido presencia de seres del Otro Mundo, en 
nes buenas, emanadas de Dios, y los demás quedan como producto de fuerzas diabólicas.

Por eso, en "Estormi" aparece mezclada la idea del aparecido de carne y hueso con la fuerza del demonio.

Hay que añadir, por otra parte, que para el cristianismo medieval los difuntos constituyeron el centro de una lucha ideológica que trataba de sustituir el culto pagano de los ancestros por ritos funerarios cristianos, en los cuales la veneración a los santos remplazaría la que recibían los antepasados y los genios familiares (en el interior de las casas, los altares dedicados a los ancestros fueron ocupados por los santos [Lecouteux, Fantômes et revenants, 10 y Schmitt, "Les masques, le diable, les morts"]). La devoción a los santos cobra sin embargo características especiales, pues éstos no se hallan del todo muertos, son ministros y embajadores entre este mundo y el Paraíso; tienen una identidad ambivalente, están materialmente presentes en la Tierra a través

\footnotetext{
la tradición medieval se habla de las huestes o el cortejo de Hellequin, descrito como un desfile carnavalesco de almas hacia el Más Allá. Como explica este crítico, Hellequin constituye, en realidad, una transformación de esos "dioses atadores" de la mitología indoeuropea, capaces de dirigir los destinos de los hombres a su voluntad, y es análogo a aquellas divinidades celtas que poseen poderes mágicos (su atributo principal, el mazo con el que siempre se le representa, es el instrumento con el que puede prolongar o terminar la vida de los hombres, al igual que cambiar su apariencia. Walter lo relaciona tanto con el mazo de la representación del hombre salvaje — cuyas fechas de aparición coinciden con ciertos rituales: San Silvestre, 10 de enero; San Juan, primero de mayo; solsticio de verano; día de muertos...como incluso con los poderes detentados por la célebre varita mágica de las hadas). Hellequin con su cortejo no es, pues, sino la encarnación cristianizada de un viejo mito pagano de apariciones del Más Allá que la Iglesia no puede asimilar más que a través de su demonización, por lo que el personaje se transforma en el temible señor de una tropa de guerreros ávidos de cadáveres arrepentidos de sus pecados y arrastrados al infierno, figura ligada a las brujas (así como múltiples hadas celtas se convirtieron en brujas bajo la mirada medieval cristiana $-i$. e. Morgana). Véase al respecto Walter, "La Mesnie Hellequin" y supra nota 19, además de la reciente edición de Karin Ueltschi, La Mesnie Hellequin en conte et en rime, Paris, Champion, 2008. Augustin Redondo hace un buen resumen de este tema y su relación con la tradición hispánica en "Las tradiciones hispánicas de la 'estantigua' ('cacería salvaje' o mesnie Hellequin) y su resurgencia en el Quijote". Agradezco a Gabriela Nava esta última referencia.
} 
de sus cuerpos convertidos en reliquias milagrosas - es decir, físicamente activas - y por otra parte ya se encuentran en el paraíso (Binski, Medieval Death, 12). De esta manera parecen transgredir la separación de los ámbitos de la vida y la muerte, funcionando como intercesores entre ambos.

Asimismo, con la creación del Purgatorio ocurre otro fenómeno donde también se traspasan los límites de uno y otro ámbito. La idea de este "tercer lugar", a su vez, implica una clara noción de la corporeidad de los muertos, ${ }^{24}$ quienes van a sufrir en carne viva las diferentes torturas que castigan sus pecados previos (para Lecouteux es el Purgatorio adonde van a dar todos los aparecidos paganos).

Pero junto al temor que los muertos siempre inspiraron a los vivos surge una nueva relación: el poder de los vivos sobre los muertos, pues las plegarias de unos acortan las penitencias de los otros. ${ }^{25}$ Le Goff menciona los pactos que surgen con el compromiso de que el primero que muera deberá volver para narrar a sus amigos lo que vea en el Más Allá, en el entendido de que el vivo contribuiráa la liberación de la penitencia... (Elnacimiento, 212; véase también Varvaro, Apparizioni Fantastiche).

Boccaccio parodia esta clase de pactos en el relato VII-10 del Decamerón, donde un aparecido que viene a confirmar a su mejor amigo que no hay mayor castigo por tener relaciones entre comadre y compadre. De hecho, numerosas historias de esta obra aluden burlescamente a varios tópicos ligados con los muertos: desde la profanación de tumbas (con el temor de que los difuntos reaccionen, como en la historia de Andreuccio [II5]), así como la exhumación de cadáveres (IX-1), hasta diverti-

24 "Se dotó a las almas separadas de una materialidad sui géneris y las penas del Purgatorio pudieron de esta forma atormentarlas algo así como corporalmente" (Le Goff, El nacimiento, 15).

${ }^{25}$ Los sufragios por los muertos suponen la constitución de vastas solidaridades de una y otra parte de la muerte, relaciones estrechas entre vivos y difuntos y la existencia de instituciones de vinculación entre unos y otros que financien los sufragios, como por ejemplo los testamentos (El nacimiento, 22). 
das mofas a las creencias en aparecidos, que se consideran como propias de los ignorantes y pueblerinos ("la gente zafia del pueblo”, III-8 §37, o VII-1), como en el caso de la dama que hace pensar a su bobo marido que quien se ha acercado a la casa es un fantasma y no su amante desprevenido, y en este caso la infiel se da incluso el lujo de inventar en el momento una supuestamente conocida plegaria para "desaparecer fantasmas" (VII-1), ${ }^{26} \mathrm{O}$ bien aquel abad que para ir y venir de la casa de una viuda con quien tiene una aventura usa las ropas del marido difunto, por lo que todos los vecinos consideran que se trata del muerto que ronda su casa como cualquier aparecido tradicional ${ }^{27}$ y no se preocupan más por el hecho (III-8). ${ }^{28}$

${ }^{26}$ José Manuel Pedrosa examina la larga tradición folclórica y de la antigüedad clásica de este motivo en su bien documentado trabajo sobre "La adúltera y el conjuro", donde menciona, además de la costumbre — tal vez etrusca, precisada por Giardini, gran comentaristas del Decamerón - "de plantar una calavera de burro en cultivos y en viñedos para espantar tormentas, malos espíritus y males de ojo" (Giardini apud Pedrosa, "El conjuro", 127; Maria Pia Giardini, Tradizioni popolari nel "Decameron”, Florencia, Olschki, 1965, 28-29). Véase también la nota 13 de la edición de María Hernández, del Decamerón, 759.

${ }^{27}$ En su trabajo sobre "Los fantasmas enamorados", Pedrosa menciona la reutilización de este motivo en diversas comedias del Siglo de Oro español, desde Luis Vélez de Guevara y Calderón, así como en relatos en prosa de los siglos XVII y hasta del xx, además de demostrar su pervivencia hasta la actualidad en una multiplicidad de ejemplos de relatos de tradición oral españoles y de toda Hispanoamérica. Es curioso que los ejemplos del s. XVII comparten todos una cierta postura ante el motivo, donde el disfraz ultramundano sirve para proteger un amor contrariado, y al final, en general, alguien apoya a los amantes y devuelve "la armonía a la comunidad", mientras que en Boccaccio el motivo se conjuga más bien con una evidente intención burlesca de criticar al clero lujurioso, independientemente de que el disfraz siga estando justificado, como en los ejemplos anteriores, no tanto por la imposición de una pareja no deseada como por la risible tontería del marido que sufre los efectos del engaño, lo que también se matiza con la crítica, muy bocaciana y ya mencionada, a la ignorancia y las supersticiones populares.

${ }^{28}$ Partiendo de la noción, generalizada durante el medioevo, que supone que los difuntos no están nunca del todo muertos, sino que "después de su deceso, [...] siguen viviendo con una vida que se parece a la nuestra y vuelven a los lugares en que se desarrolló su existencia..." (Delumeau, El miedo, 128; y véase también Lecouteux, Au-delà, 96 ss., quien aduce en prueba los dones funerarios — armas, muebles, comida - de las tumbas), Delumeau explica así, historias como la de don Juan y el 
Pero como ya se ha mencionado, ante la necesidad de desmantelar las creencias paganas la postura oficial fue involucrar al diablo, a quien se atribuiría la capacidad de engañar a los humanos a través de toda clase de transformaciones ilusorias, a veces seductoras y otras simplemente aterradoras, además de causar visiones fantasiosas de apariciones (Delumeau, El miedo, 124). ${ }^{29}$

El paso de los aparecidos a los seres diabólicos nos llevará a un pequeño ejemplo del funcionamiento de la parodia de dichos fenómenos, evidente en las Cent Nouvelles nouvelles, obra análoga al Decamerón pero francesa y del siglo xv, formada por un conjunto de relatos en su mayor parte graciosos que sin embargo, como en el caso de la obra italiana, también admite otros didácticos y moralizadores. Encontramos así una narración de corte aleccionador (la nouvelle 70), en donde un caballero, habiendo reflexionado sobre las palabras del bautismo, considera el sacramento tan poderoso para protegerlo de cualquier demonio sin necesidad de persignarse - gesto que constituía la protección a la que acudiría normalmente cualquier cristiano ante una aparición diabólica. Y en efecto, una noche, estando en el retrete se aparece ante el protagonista un monstruo de ojos centelleantes y cuernos, que el narrador no sabe identificar pero supone que es un diablo. ${ }^{30}$ El simple recuerdo de las palabras del bautismo, el poderoso "escudo de la fe", ${ }^{31}$ permite al caballero, después de una lucha que le deja más de una magulladura, arrancar uno de los cuernos al demonio y obligarlo a huir.

Esta narración ha sido analizada por Beardsmore como una historia de fantasmas que marca el contenido edificante y proseli-

\footnotetext{
"convidado de piedra", además de la convicción de la existencia de los vampiros en algunas regiones.

${ }^{29}$ Cfr. Schmitt, "Les masques, le diable, les morts", quien discute la distinción entre las apariciones de difuntos y las máscaras diabólicas.

30 "c'estoit ung monstre tresespoventable, et ung dyable, comme je croy", líneas 76-77 ["era un monstruo aterrador y creo que era un diablo"]. El énfasis es mío.

31 "son bon escu de ferme foy", línea 89.
} 
tista de este tipo de relatos durante la Edad Media. Es interesante notar, sin embargo, que dos páginas más adelante, la nouvelle 72 retoma el tema pero invirtiendo todos sus principios, ya que se trata aquí de una típica narración de triángulo amoroso en la que el marido llega inesperadamente a su casa, por lo que el amante se ve obligado a esconderse en el retrete. Presa de un ataque de tos, no le queda más remedio que introducir la cabeza por el agujero, con lo que, como describe el narrador, "quedó todo embadurnado con la mermelada que ahí había";32 para colmo, al incorporarse se le atora la cabeza, por lo que termina con un collarín involuntario y maloliente alrededor del cuello. Sin embargo, esto último le proporciona la idea de su huida: pide a la dama que acabe de embadurnarle la cara hasta dejársela "más negra que el carbón" — color típico del diablo_-, y tomando su espada —otro rasgo demoniaco (ver Russell, Lucifer, 69) y sin mencionar la pestilencia, que debió añadir un toque muy realista a la creencia en los infernales aromas de los seres satánicos_-, sale ruidosamente y de improviso hacia donde se encontraba el marido, quien "siente enorme pavor, pensando que era un diablo" 33 y aterrado cae al suelo preguntándose de dónde vendría y quién lo enviaría.

Retomando pues, el mismo lugar de la acción del relato didáctico, ${ }^{34}$ esta narración reutiliza los elementos de la anterior, rebajándolos y burlándose de ellos: a la terrorífica descripción del diablo de ojos encendidos y cuernos opone la máscara de excremento y el cuerpo deformado por un trozo de retrete. A la lucha valerosa del caballero defendido por su fe opone un marido cornudo, despavorido y ridiculizado, tirado por los suelos.

32 “...il fut bien encensé, Dieu le scet, de la conficture de leens”, líneas 77-78.

33 “...qui eut de le veoir [si] grand paour, cuidant que ce fust ung dyable”, líneas 110-112.

${ }^{34} \mathrm{Si}$ bien el retrete resulta un lugar ideal para la aparición de seres fantasmagóricos, por lo aislado y oscuro del lugar, queda claro que no deja de convertirse en un motivo fácilmente parodiable. 
Al asombro y reverencia de los que oyeron la historia del primer caballero se opone la actitud burlona de la esposa infiel, quien al final de la historia continuó haciendo con aquel diablo eso "que tan gustosamente todos hacen". ${ }^{35}$

Mucho se ha discutido la estrategia de reutilizar material narrativo tradicional para la composición de los relatos cortos medievales (vid.Azuela, Del "Decamerón" a las "Cent Nouvelles", 124-128 y passim), que deriva en el uso paródico de los diversos motivos de los géneros serios. Así pues, las aquí mencionadas son, pues, algunas muestras del tipo de subversión que los textos cómicos podían realizar con respecto a los relatos aterradores acerca de los aparecidos. Si la Iglesia había reutilizado las apariciones de los paganos para considerarlas productos infernales que al intimidar a los fieles se volvían apoyos infalibles para acrecentar su temor al pecado, los relatos cómicos reutilizaban a su vez esos argumentos, ya fuera para ridiculizarlos y con ello conjurar el miedo que podían producirles, ${ }^{36}$ o bien, como en los ejemplos aquí citados de las nouvelles, para celebrar la astucia que los pecadores ponían en juego con el fin de satisfacer toda clase de placeres corporales y materiales - placeres que constituían el tema principal de estos géneros.

Y será justamente el tema de lo corporal el que nos permitirá concluir este trabajo, volviendo a la primera historia mencionada, la de Estormi, donde la proliferación de los cuerpos difuntos y su materialidad ineludible parecen subrayar justamente esta oposición entre lo espiritual y lo carnal que caracteriza a los

\footnotetext{
35 "Et depuis continua avec le dyable dessus dit le mestier que chacun fait voluntiers" (líneas 132-134) [“y en adelante, continuó haciendo con el diablo ya mencionado el oficio que todos hacen gustosamente"]. Cierre que comparte además el tono de varios del propio Boccaccio (Cfr. Azuela, Del "Decamerón" a las "Cent Nouvelles", cap. IV).

${ }^{36}$ Lacarra ("Elementos"), y Russell (Lucifer, 74-76) hablan del contenido jocoso de muchos exempla, donde el diablo es vencido y ridiculizado de divertidas maneras, como un medio para conjurar el temor de los fieles.
} 
géneros cómicos con respecto a los géneros edificantes, que al cabo pertenecen al mismo linaje. Sabemos, en efecto, que los $f a$ bliaux y las nouvelles no pueden negar su filiación con los exempla quelos anteceden, y cuyas anécdotas muchas veces comparten. De hecho, en la mayor parte de las ocasiones, estos relatos cómicos concluyen con la inserción de una moraleja, que para Stone no es sino un intento de transferir la atención del público o lector de lo material hacia lo espiritual, de lo contingente a lo universal. El narrador, afirma Stone, redime así su texto profano en una afirmación convencional y ritualizada que el crítico analoga a la conversión del impío en su lecho de muerte ("The Insistence", 458). Sin embargo, uno de los rasgos más notorios de varias de las moralejas añadidas a los relatos cómicos es su incongruencia con el contenido inmoral de los mismos, con lo que nos encontramos ante una especie de ironía que aparece en los momentos en que se pretende acercar el relato humorístico a la tendencia aleccionadora. Como si el propio texto desmantelara el contenido didáctico de su conclusión. En otro lugar he examinado este fenómeno, relacionándolo con la resistencia de los autores de nouvelles a imponer una carga didáctica a textos cuyo interés debería ser puramente literario (vid. Azuela, "El mensaje de las nouvelles. De la edificación al pasatiempo", Del "Decamerón" a las "Cent Nouvelles", 163-225). En el caso de Estormi nos encontramos con una doble moraleja, que según Stone obedece a la conciencia del narrador de la imposibilidad de ocultar el contenido profano y material de la historia. Por más que todo gira en torno al intento de sepultar o encubrir los cadáveres y lo específicamente corporal del propio género de los $f a$ bliaux, los cuerpos regresan infaliblemente, al grado de que la propia intriga planeada por el tío de Estormi resulta deficiente, pues en el intento de silenciar las pruebas materiales de su asesinato no hace sino provocar un nuevo crimen, y la presencia de un nuevo cuerpo que otra vez es necesario disimular. Sin embargo, la primera moraleja de la historia sólo apuntaba hacia la 
corrupción de los miembros de la Iglesia, que reciben un merecido castigo por su inagotable lujuria. Pero casi sin transición se añade la nueva moraleja, como si el propio narrador se percatara de que su primer mensaje didáctico no daba cuenta de la totalidad del relato, por lo que su segunda moraleja gira alrededor de Estormi, modelo de esos parientes pobres a los que no hay que ignorar, pues siempre pueden resultar de utilidad (vv. 622-625). Parecería así que quien narra se resigna a que el joven ocupe el lugar de honor en una narración donde fue justo él quien añadió un nuevo e inesperado cuerpo a la intriga, pues cual buen lector de cada detalle de la historia preparada por su tío, Estormi fue capaz de interpretar a su vez los datos de la realidad que se le presentaban, y al ejecutar al último cura sólo actuó de acuerdo con el cuento que le habían hecho creer. Aparte de añadir un cadáver a la intriga, Estormi termina, pues, por revelar una vez más la materialidad misma de los temas que acaso la primera moraleja tal vez trataba de hacer olvidar, al elevarse al sentido general de la historia.

Este trabajo pretendía presentar un cruce de fronteras entre lo serio y lo cómico en historias en donde habitantes del Más Allá traspasan los confines entre su universo y este mundo; la intersección entre lo material y corpóreo y los seres de ámbitos espirituales nos ha llevado a otro cruce de fronteras, en el fondo muy usual para quienes trabajamos con textos literarios: el de los límites del propio texto, en donde es inevitable asistir al entrecruzamiento del trabajo del narrador y de quien lo lee o escucha. La apropiación por parte de los receptores, que reciben, difunden o interpretan a su vez una narración se ejemplifica en "Estormi". Pero como vimos, esta reapropiación no sólo sucede en esa historia, sino en general en la reinterpretación realizada por los géneros cómicos que reutilizan los motivos edificantes. $^{37}$

\footnotetext{
${ }^{37}$ Este artículo estaba ya en proceso de publicación cuando apareció la colección
} 


\section{REFERENCIAS}

Azuela, Cristina, Del "Decamerón" a las "Cent Nouvelles nouvelles". Relaciones y Transgresiones en la nouvelle medieval, México, Universidad Nacional Autónoma de México, Instituto de Investigaciones Filológicas, 2006.

Beardsmore, Barry, F., "About the Seventieth of the Cent Nouvelles nouvelles", Romania 110:1-2, 1989, 233-244.

Binski, Paul, Medieval Death. Ritual and Representation, Ithaca-New York, Cornell University Press, 1996.

BLoch, Howard, The Scandal of the Fabliaux, Chicago, The University of Chicago Press, 1986.

Boccaccio, Giovanni, Decameron, Vittore Branca (ed.), Milán, Mondadori Editore, 1985.

— - Decamerón, trad. María Hernández Esteban, Madrid, Cátedra, 2001 (Letras Universales).

Cent Nouvelles nouvelles (Les), Franklin P. Sweetser (ed.), Genève, Droz, 1966.

Delumeau, Jean, Elmiedo en Occidente [1978], Madrid, Taurus, 1989.

"Estormi", en Nouveau Recueil Complet des Fabliaux (NRCF), Willem Noomen y Nico van den Boogaard (ed.), Assen, Van Gorcum, 1983, tomo 1, 1-28.

Fabliaux. Cuentos franceses medievales, edición bilingüe de Felicia de Casas, Madrid, Cátedra, 1997.

Fabliaux du Moyen Âge, Jean Dufournet (ed.), Paris, Garnier Flammarion, 1998 [edición bilingüe en francés medieval y moderno].

Kelly, Henry A., The Devil at Baptism: Ritual, Theology and Drama, Ithaca, London, Cornell University Press, 1985.

LaCARra, María de Jesús, "'De la disciplina en el reír': santos y diablos ante la risa", en Pensamiento medieval hispano. Homenaje a Horacio Santiago Otero, José María Soto Rábanos (ed.),

de artículos editados por Karin Ueltschi y Myriam White-Legoff, Les entre-mondes. Les vivants, les morts (Klincksieck, 2009). Agradezco a los estudiantes Karina Castañeda, Paulina Matamoros y Yoshiro Tanaka por su apoyo técnico durante la revisión de este trabajo, así como a la cuidadosa lectura de Gabriela Nava. 
Madrid, Consejo Superior de Investigaciones Científicas, 1998, 377-391.

Lacarra, María de Jesús, "Elementos cómicos en los cuentos medievales castellanos", Tigre 6 (Travaux des hispanistas de L'Université Stendhal), 1991, 31-47.

Lecouteux, Claude, Fantômes et revenants au Moyen Âge [1988], Paris, Imago, 1996 (publicado en español como Fantasmas y aparecidos en la Edad Media, Barcelona, Olañeta, 1999).

__ Au-delà du merveilleux. Essai sur les mentalités du Moyen Âge, Paris, Presses de l'Université de Paris-Sorbonne, 1998.

LE Goff, Jacques, Elnacimiento del Purgatorio, Madrid, Taurus, 1981.

LORCIN, Marie-Thérèse, "Les revenants dans les fabliaux", Reinardus 2 (2), 1989, 91-101.

Pedrosa, José Manuel, "El conjuro de la adúltera (Ат 1419H.): del cuento y la canción orales a la tradición escrita (entre Boccaccio, Timoneda, Cervantes y Lorca)", en Formas narrativas breves en la Edad Media: Actas del IV Congreso, Santiago de Compostela, 8-10 de julio de 2004, E. Fidalgo (coord.), Santiago de Compostela, Universidad, 2005, 123-148.

, "Los fantasmas enamorados: Job, Vélez de Guevara, Calderón, Castillo Solórzano, Zayas, Feijoo, Cruz, Irving (y la tradición folclórica)", en El Siglo de Oro en escena. Homenaje a Marc Vitse, Odette Gorsse y Frédéric Serralta (ed.), Toulouse, Presses Universitaires du Mirail (Anejos de Criticón, 17), Consejería de Educación de la Embajada de España en Francia, 2006, 733745 .

__ , "Una leyenda gallega de fantasmas (siglo XI), dos leyendas chinas de fantasmas (siglos III-V) y una leyenda urbana internacional", Nueva Revista de Erudición y Crítica 1, 2006, 101-106.

REDONDO, Augustin, "Las tradiciones hispánicas de la 'estantigua' ('cacería salvaje' o mesnie Hellequin) y su resurgencia en el Quijote", en Otra manera de leer el "Quijote": historia, tradiciones culturales y literatura, Madrid, Castalia, 1998 (Nueva Biblioteca de Erudición y Crítica, 13).

Russell, Jeffrey B., Lucifer, The Devil in the Middle Ages, IthacaLondon, Cornell University Press, 1984.

Schмiтt, Jean-Claude, "Les masques, le diable, les morts dans l'Occident médiéval", Razo 6, 1986, 87-117. 
Stone, Gregory B., "The Insistence of the Body in the Old French Fabliau Estormi", Exemplaria 2 (2-october), 1990, 449-473.

VarVaro, Alberto, Apparizioni Fantastiche. Tradizioni folcloriche e letteratura nel Medioevo, Walter Map, Bologna, Mulino, 1994. Walter, Philippe, Le mythe de la chasse sauvage dans l'Europe Médiévale, Paris, Champion, 1997.

__, "La Mesnie Hellequin. Mythe calendaire et mémoire rituelle", Iris 18, 1999, 51-71.

—_ Mitología cristiana. Fiestas, ritos y mitos de la Edad Media [2004], Buenos Aires, Barcelona, México, Paidós, 2005. 